\title{
INVESTIGATING THE IMPACT OF SOILS' PHYSICOCHEMICAL COMPOSITION ON CHLORSULFURON PEDOSPHERIC SORPTION
}

\author{
KHURAM SHAHZAD AHMAD
}

\begin{abstract}
Chlorsulfuron (1-(2-chlorophenyl) sulfonyl-3-(4-methoxy-6-methyl1, 3, 5- triazin-2-yl)), a Sulfonyl herbicide was investigated for its sorption behaviour in soils from various geographical locations. The results, fitting Freundlich and Linear equations, depicted a $\mathrm{C}$ type curve. Linear distribution coefficient value $\left(\mathrm{K}_{\mathrm{d}}\right)$ spanned in a range of $8.2-23.0 \mu \mathrm{g} / \mathrm{ml}$ while Freundlich distribution coefficient value $\left(\mathrm{K}_{\mathrm{f}}\right)$ was found to be $7.06-17.41 \mu \mathrm{g} / \mathrm{ml}$. Low Gibbs free energy values (-14.9 to $-16.0 \mathrm{~kJ} / \mathrm{mol})$ are indicative of physisorption process. The regression and correlation analysis depicted $\mathrm{pH}$ to be negatively correlated ( $r=-0.936)$ while organic matter and organic carbon to be positively correlated with $\mathrm{K}_{\mathrm{d}}$ ( $\mathrm{r}=0.989$ and $\mathrm{r}=0.988$ respectively). However the soil texture rendered positive correlation with clay $(r=0.897)$ and negative correlation with sand and silt ( $r=-0.990$ and $r=-0.820$ respectively). Desorption hysteresis coefficient $(\mathrm{H})$, in all four soil was found to be less than 1 (0.44 to 0.62). Results have been statistically evaluated by ANOVA and the accuracy of fit has been calculated by plotting residual graphs in Minitab. This study is a milestone for further investigation based on Chlorsulfuron degradation and mobility patterns.
\end{abstract}

Keywords: Chlorsulfuron methyl, Soil, Adsorption, Correlation, Regression

\section{INTRODUCTION}

Weed control is an imperative factor for an effective crop production and therefore the prevention of weed-crop competition at an early stage plays a very paramount role [1]. Sulfonylurea (SU) herbicides are group of herbicides,

\footnotetext{
a Department of Environmental Sciences, Fatima Jinnah Women University, The Mall, 46000, Rawalpindi, Pakistan. Tel \#:92 (051) 9292900, Email: chemist.phd33@yahoo.com
} 
recently manufactured and the preeminent qualities of these weedicides include their rather immensely active nature and very low application rates [2]. Long term application of sulfonylurea herbicides often cause curtailment in crop yield annually as well as emergence of resistant weed species to herbicides application $[3,4]$. Boost in crop yields has been observed by using pesticides yet it also posed challenges to food and environmental contamination [5]. Chlorsulfuron has been the first sulfonylurea herbicide in terms of commercialization. Chlorsulfuron finds major applicability for wiping out multiple weed species and is also used as a pre-emergent and postemergent herbicide on variety of weeds attacking the cereal crops $[6,7,8]$. Chlorsulfuron possess minor toxicity for mankind and other faunal species. It is known for obstructive response for enzyme acetolactate synthase (ALS) which is aimed at biosynthetic protein pathways in floral and microbial species. Chlorsulfuron application rates for weed destruction can have an influential impact on microbe mediated processes thus different doses rates have been recommended for Chlorsulfuron use [9]. Several floral and microbial populations exhibited resistance towards Chlorsulfuron which is mostly associated with point mutations rendered in ALS thus causing hindrance between Chlorsulfuron and acetolactate synthase attachment [10,11]. Recently number of floral species i.e. 103 monocotyledonous and 143 dicotyledonous has been found resistant to ALS impeders like Chlorsulfuron [12]. Like all other ALS-impeder herbicides, Chlorsulfuron toxicity towards plants and persistence is influentially governed by organic matter. Higher quantity of organic matter favors alleviated toxicity and reduced dispersal in soil compartment [13]. Residual herbicide quantities have given rise to their use particularly in case of grain and leguminous crops. Chlorsulfuron migratory patterns enabling its occurrence away from areas of application has been influenced by several factors. Thus Chlorsulfuron application has been completely restricted in several regions [14, 15]. Despite massive use of pesticides in an agricultural country like Pakistan, the reported data is scant in many aspects [16]. Drawing a clear cut trend for Chlorsulfuron mitigation in contaminated soils on larger scale is impossible without comprehension of its sorption behaviour. Thus present study took into account this scant knowledge by investigating sorption behaviour of Chlorsulfuron in selected soils and to draw a clear environmental trend depicting the dependence of sorption on soils' physicochemical characteristics. 
INVESTIGATING THE IMPACT OF SOILS' PHYSICOCHEMICAL COMPOSITION ON ...

\section{RESULTS AND DISCUSSION}

\section{Variation in soils' physicochemical make up}

Table 1. Physicochemical parameters of selected soils

\begin{tabular}{|c|c|c|c|c|c|c|c|c|c|c|}
\hline Soil & $\mathrm{pH}$ & $\begin{array}{c}\mathrm{OM} \\
(\%)\end{array}$ & $\begin{array}{c}\text { TOC } \\
(\%)\end{array}$ & $\begin{array}{c}\mathrm{N} \\
(\%)\end{array}$ & $\begin{array}{c}\text { Clay } \\
(\%)\end{array}$ & $\begin{array}{c}\text { Sand } \\
(\%)\end{array}$ & $\begin{array}{c}\text { Silt } \\
(\%)\end{array}$ & CEC & Texture & $\begin{array}{c}\mathrm{EC} \\
(\mu \mathrm{s} / \mathrm{cm})\end{array}$ \\
\hline 1 & 7.41 & 2.29 & 1.33 & 0.137 & 26 & 20.48 & 53.52 & 7.1 & Silty loam & 707 \\
\hline 2 & 6.2 & 3.5 & 2.03 & 0.14 & 60.52 & 15 & 24.48 & 7.4 & Clay & 272 \\
\hline 3 & 6.60 & 2.82 & 1.63 & 0.092 & 57 & 19 & 24 & 7.83 & clay & 232 \\
\hline 4 & 7.38 & 2.74 & 1.59 & 0.083 & 40.94 & 6.3 & 52.76 & 7.9 & Silty loam & 189 \\
\hline
\end{tabular}

(OM: organic matter, TOC: Total Organic Carbon, CEC: Cation exchange capacity, EC: Electrical conductivity)

Soils sampled from geographically diverse zones were tested for variation in physicochemical characteristics (Table 1). This degree of variation was expressed in terms of all tested parameters with Soil 2 exceeding all samples in lowest $\mathrm{pH}(6.2)$, highest OM and TOC (3.5\% and $2.03 \%)$, highest clay content $(60.52 \%)$. This was due to the fact that the sample was taken from an agricultural region and the vegetation results in an increase in the soil OM. The value of kinetic parameters increases with the increasing clay content [17]. Selected soils followed the trend Soil2> Soil3> Soil4> Soil1 for above mentioned parameters. The values of EC varied among all soils and were in the range $189-707 \mu \mathrm{s} / \mathrm{cm}$. Higher variability in EC values has been reported for several soils thus altering pesticide adsorption [18]. The organic matter (OM) in all the samples was found not to be in a higher range (2.29$3.5 \%)$.

\section{Variable sorptive affinities}

Table 2. Adsorption coefficients of Chlorsulfuron in selected soils

\begin{tabular}{|c|c|c|c|c|c|c|c|c|c|}
\hline Soils & $\begin{array}{c}\mathrm{K}_{\mathrm{d}} \\
(\mu \mathrm{g} / \mathrm{ml})\end{array}$ & $\mathrm{R}^{2}$ & $\mathrm{~K}_{\mathrm{oc}}$ & $\begin{array}{c}\mathrm{K}_{\mathrm{f}} \\
(\mu \mathrm{g} / \mathrm{ml})\end{array}$ & $\mathrm{R}^{2}$ & $\mathrm{~K}_{\text {foc }}$ & $\mathrm{n}_{\mathrm{a}}$ & $\mathrm{K}_{\mathrm{om}}$ & $\begin{array}{c}\Delta \mathrm{G} \\
(\mathrm{kJ} / \mathrm{mol})\end{array}$ \\
\hline 1 & 8.2 & 0.92 & 850.0 & 7.06 & 0.83 & 732.35 & 1.22 & 425.80 & -14.9 \\
\hline 2 & 23.0 & 0.98 & 1440.5 & 17.41 & 0.87 & 1093.39 & 1.60 & 635.70 & -15.9 \\
\hline 3 & 15.1 & 0.9 & 1271.6 & 13.6 & 0.99 & 1137.03 & 1.32 & 661.70 & -16.0 \\
\hline 4 & 12.0 & 0.95 & 1121.0 & 9.32 & 0.74 & 867.27 & 1.90 & 504.23 & -15.4 \\
\hline
\end{tabular}


Photometric determination of Chlorosulfuron adsorption and desorption was done at $\lambda_{\max } 230 \mathrm{~nm}$ on UV-Vis Spectrophotometer BMS 1602. The adsorption and desorption isotherms of Chlorsulfuron in all tested soil samples yielded nonlinear and Freundlich isotherm that resemble to C-type isotherm shape (figure 1-4). This type of isotherm usually depicts the interaction of hydrophobic adsorbate with hydrophobic adsorbent (e.g. pesticide-organic matter interactions). Adsorption equilibrium distribution co-efficient $\left(\mathrm{K}_{\mathrm{d}(\mathrm{ads})}\right)$ was calculated by plotting the adsorbed pesticide concentration $\left(C_{s}\right)$ against the equilibrium pesticide concentration $\left(\mathrm{C}_{\mathrm{e}}\right)$ and are shown in the Table 2. Similarly the desorption equilibrium distribution co-efficient $\left(\mathrm{K}_{\mathrm{d}(\mathrm{des})}\right)$ was calculated by plotting the desorbed pesticide concentration $\left(\mathrm{C}_{\mathrm{s}}\right)$ against the equilibrium pesticide concentration $\left(\mathrm{C}_{\mathrm{e}}\right)$. The distribution coefficients $\left(\mathrm{K}_{\mathrm{d}}\right)$, Freundlich constant $\left(K_{f}\right)$, Gibbs free energy $(\Delta G)$ and hysteresis $(H)$ were calculated from the obtained isotherms.

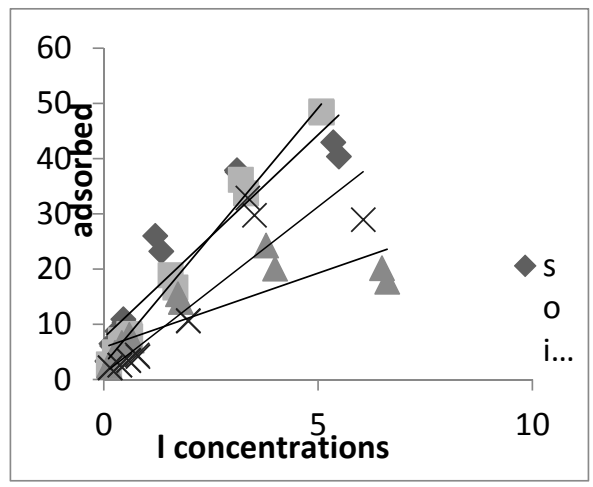

Figure 1. Comparative linear adsorption isotherms of Chlorsulfuron on studied soils

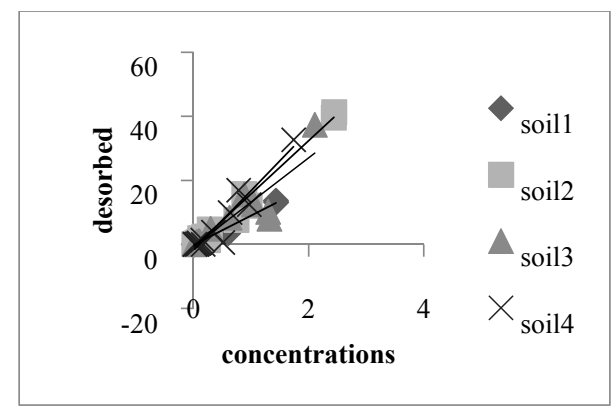

Figure 3. Comparative linear desorption isotherms of Chlorsulfuron on studied soils

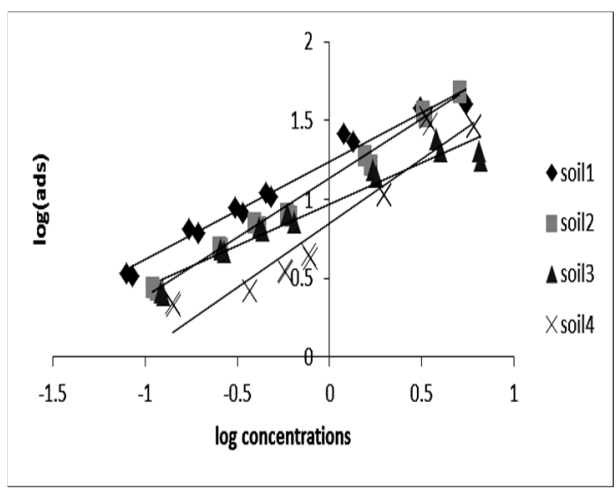

Figure 2. Comparative Freundlich adsorption isotherms of Chlorsulfuron on studied soils

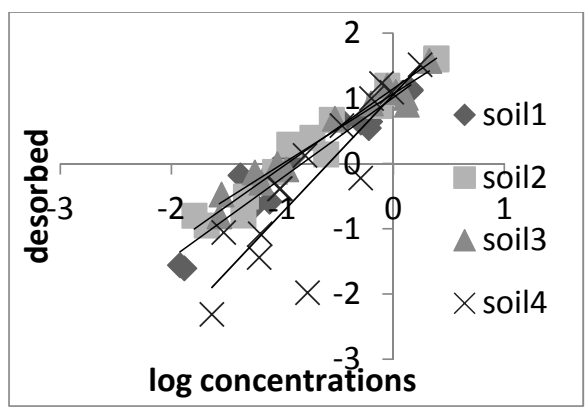

Figure 4. Comparative Freundlich desorption isotherms of Chlorsulfuron on studied soils 
$\Delta G$ values $(-14.9$ to- $16.0 \mathrm{~kJ} / \mathrm{mol})$ of soil in the current investigation falls in lower range, indicating the fact that lower values of Gibbs free energy results in weak interaction between soil and pesticide. Thus they experience Van der-Waals forces among them. Consequently we can say that the phenomenon of physisorption is existent. The value of $\Delta G<0$ is indicative that the reaction is favourable and spontaneous. It also predicts the duration of Chlorsulfuron endurance in soil as factors like transportation, bioavailability and degradation are influenced by adsorption. A positive correlation has been observed between Freundlich constant $\left(\mathrm{K}_{\mathrm{f}}\right)$ and the distribution coefficient $\left(\mathrm{K}_{\mathrm{d}}\right)$. Both were observed to be increasing in s similar pattern. $K_{d}$ also represents the sorption of Chlorsulfuron in soil. The range of $R^{2}$ of $K_{d}$ is from 0.9-0.98 while that of $\mathrm{K}_{\mathrm{f}}$ was seen to be $0.74-0.99 . \mathrm{R}^{2}$ can be used to select the best fitting model for adsorption and desorption. Soil 2 show cased highest value of linear distribution coefficient $\mathrm{K}_{\mathrm{d}} 23 \mu \mathrm{g} / \mathrm{ml}$ and Freundlich distribution coefficient $\left(\mathrm{K}_{\mathrm{f}}\right)(17.4 \mu \mathrm{g} / \mathrm{ml})$ which is indicative of high rate of adsorption. A positive correlation has been observed between $\mathrm{K}_{d} / \mathrm{K}_{\mathrm{f}}$ and OM. So it can be incurred that the highest $\mathrm{K}_{\mathrm{f}}$ in soil 2 may be due to the fact that it contains the highest amount of OM (3.5\%), this trend has been reported for other pesticides [19, 20]. $\mathrm{K}_{\mathrm{f}(\mathrm{ads})}$ ranges for adsorption of Chlorsulfuron from $7.06-17.41 \mu \mathrm{g} / \mathrm{ml}$. The rise in $\mathrm{K}_{\mathrm{f}}$ is because of higher Soil Organic Matter (SOM), $\mathrm{pH}, \mathrm{CEC}$ and clay percentage in soils makes soil 2 best adsorbent as reported [21]. The overall trend of increasing $K_{f}$ and $K_{d}$ for present investigation was Soil2> Soil3> Soil4> Soil1.

\section{Desorption}

Table 3. Desorption coefficients of Chlorsulfuron in selected soils

\begin{tabular}{|c|c|c|c|c|c|c|c|c|}
\hline Soils & $\begin{array}{c}\mathrm{K}_{\mathrm{d}(\mathrm{des})} \\
(\mu \mathrm{g} / \mathrm{ml})\end{array}$ & $\mathrm{R}^{2}$ & $\mathrm{~S}$ & $\begin{array}{c}\mathrm{K}_{\text {f(des })} \\
(\mu \mathrm{g} / \mathrm{ml})\end{array}$ & $\mathrm{R}^{2}$ & $\mathrm{~S}$ & $\mathrm{n}_{\mathrm{d}}$ & $\mathrm{H}$ \\
\hline 1 & 11.67 & 0.98 & 1.76 & 14.10 & 0.95 & 0.174 & 0.83 & 0.62 \\
\hline 2 & 7.83 & 0.91 & 2.79 & 11.50 & 0.72 & 0.631 & 0.55 & 0.44 \\
\hline 3 & 8.24 & 0.97 & 0.789 & 10.28 & 0.92 & 0.238 & 0.81 & 0.50 \\
\hline 4 & 11.42 & 0.80 & 4.492 & 11.80 & 0.95 & 0.161 & 0.93 & 0.48 \\
\hline
\end{tabular}

Soils that succeeded in having good adsorption rates i.e. Soil 2 and 3 were found poor for desorbing the attached Chlorsulfuron molecules. Stronger adsorption inhibited these soils from desorbing the molecules readily. While Soil 1 and 4 expressed higher desorption values owning to higher $\mathrm{pH}$ and 
lower OM, TOC and clay contents.One more factor affecting the adsorption of Chlorsulfuron in soil is its $n_{a}$ value which is inversely proportional to adsorption process of soil. It depicts the intensity of adsorption. Similarly the $n_{d}$ value depicts the intensity of desorption. The desorption hysteresis coefficient $(\mathrm{H})$ of all soil samples specify slight differences among adsorption and desorption isotherms (Table 3). It was found to be ranging from 0.44 to 0.62 . However the value of $\mathrm{H}$ close to 1 indicates that the process of desorption occurred almost as quickly as adsorption. Highest value of $\mathrm{H}$ was perceived in soil2 (0.62) indicating quick desorption. This might be due to the fact that the sand content in soil2 is fairly high. The order of soil samples for desorption process was Soil1> Soil4> Soil3> Soil2.

\section{Chlorsulfuron Leaching and mobility pattern}

The $\mathrm{K}_{\mathrm{oc}}$ values of the soil samples in the study Chlorsulfuron showed relatively medium mobility demonstrating moderately less probabilities of leaching. The highest $K_{o c}$ value for Soil 2 (1440.5) is also an indicant for additional adsorption and reduced mobility in the soil. This may be beneficial to predict whether and to what extent a certain soil may be deterrent for the ground water resources underneath it. This parameter can be calculated using the 3-phase and 4-phase equilibrium partitioning models. These models are effective in calculating a precise soil concentration that safeguards the ground water. According to studies the $\mathrm{K}_{\mathrm{oc}}<50$ indicates mobility in soils to be the highest. While $\mathrm{K}_{\mathrm{oc}}$ values from 50 to 150 projected mobility to be slightly high and from 150 to 500 depicted it to be of medium mobility [22].

\section{Statistical Analysis}

Table 4. Regression and Correlation analysis for sorption properties of selected soils

\begin{tabular}{|c|l|l|l|l|l|}
\hline $\begin{array}{c}\text { Sorption } \\
\text { Coefficient }\end{array}$ & $\begin{array}{c}\text { Property } \\
(\mathrm{x})\end{array}$ & $\begin{array}{c}\text { Correlation } \\
\text { coefficient }(\mathrm{r})\end{array}$ & $\begin{array}{c}\text { Probability } \\
\text { level }(\mathrm{p})\end{array}$ & Intercept (a) & Slope (b) \\
\hline \multirow{3}{*}{$\mathrm{K}_{\mathrm{d}}$} & $\mathrm{pH}$ & -0.936 & 0.04 & 82.503 & -9.848 \\
\cline { 2 - 7 } & $\mathrm{OM}$ & 0.989 & 0.03 & -20.733 & 12.444 \\
\cline { 2 - 6 } & TOC & 0.988 & 0.03 & -20.762 & 21.48 \\
\hline
\end{tabular}


Investigations were performed to find the correlation between $\mathrm{K}_{\mathrm{d}(\mathrm{ads})}$ and the physiochemical properties of soil ( $\mathrm{pH}, \mathrm{OM}$ and TOC) (Table 4). The data was analysed for the effect of physiochemical properties on $K_{d}$ by linear regression analysis. The statistical analysis on $\mathrm{K}_{\mathrm{d}(\text { ads })}$ revealed that $\mathrm{pH}$ is negatively correlated $(r=-0.936, p<0.05)$ while OM and TOC are positively correlated with $\mathrm{K}_{d(\mathrm{ads})}(\mathrm{r}=0.989, p<0.05$ and $r=0.989, p<0.05$ respectively). Thus, lowered $\mathrm{pH}$ values increase adsorption. Consequently, $\mathrm{pH}$ values are responsible for dissociation or protonation process of pesticide and soil. While increasing $\mathrm{OM}$ and TOC values result in enhanced adsorption. The results also specified that the Soil 2 , having highest $K_{d(a d s)}$ value $(23.0 \mu \mathrm{g} / \mathrm{ml})$, contains the highest percentage of soil OM and TOC proving the fact that soil $\mathrm{OM}$ and TOC is directly proportional with the rate of adsorption occurring in that particular soil.

Table 5. Regression and Correlation analysis for different soil textures

\begin{tabular}{|c|l|l|l|l|l|}
\hline $\begin{array}{c}\text { Sorption } \\
\text { Coefficient }\end{array}$ & $\begin{array}{l}\text { Property } \\
(\mathrm{x})\end{array}$ & $\begin{array}{c}\text { Correlation } \\
\text { coefficient }(\mathrm{r})\end{array}$ & $\begin{array}{c}\text { Probability } \\
\text { level }(\mathrm{p})\end{array}$ & Intercept (a) & Slope (b) \\
\hline \multirow{3}{*}{$\mathrm{K}_{\mathrm{d}}$} & Clay & 0.897 & 0.01 & 10.739 & 0.354 \\
\cline { 2 - 7 } & Sand & -0.990 & 0.09 & 50.331 & -0.954 \\
\cline { 2 - 7 } & Silt & -0.820 & 0.05 & 21.940 & -0.160 \\
\hline
\end{tabular}

Another regression correlation was performed among $\mathrm{K}_{\mathrm{d}(\mathrm{ads})}$ and different soil textures (Table 5 ). The results indicated positive correlation among $\mathrm{K}_{d}$ and clay content of soil $(r=0.897, p<0.05)$. However sand and silt content in soil displayed negative correlation with $K_{d}(r=-0.990, p=0.09$ and $r=-0.820, p=0.05)$. This is due to the fact clay content is pivotal textural factor for adsorption of Chlorsulfuron in soil. Owing to small particle size and negatively charged surface, clay has immense surface area for ion exchange making it a good cation adsorbent.

Table 6. Univariate ANOVA analysis of Soil samples and $K_{d}$ values

\begin{tabular}{|c|c|c|c|c|c|c|}
\hline Source of Variation & SS & df & MS & F & P-value & F crit \\
\hline Between groups & 54.18 & 1 & 54.18 & 1.68 & 0.32 & 18.51 \\
\hline Within groups & 64.34 & 2 & 32.17 & - & - & - \\
\hline
\end{tabular}


The means of soil samples and adsorption distribution coefficient $K_{d}$ were analysed by one-way ANOVA, using BioStat 2009 Professional 5.7.8 statistics tool, on all four soil samples along with their $K_{d}$ values. In the univariate ANOVA sum of squares (SS), mean square (MS), F statistics (F), $P$ value and $F$ critical values ( $F$ crit) were investigated within the same groups and between groups (Table 6). For this test we assume that all observations are originating from normal distributions and all the four groups of soils have equal variances. In this regard, our $P$ value $(0.32)$ is more than the alpha value $(\alpha)(0.05)$, so the null hypothesis $\left(H_{\circ}\right)$ is not rejected in this case i.e, the assumption made earlier. It was also observed that the $F$ critical value ( $F$ crit) was found to be 18.51 . $F$ crit is the value such that any number greater than the $F$ crit value would cause us to reject our null hypothesis $\left(\mathrm{H}_{0}\right)$. In this experiment the F statistics value (1.68) falls much lower than the F crit value hence it does not lie in the rejection region.

From the residual plots we determine that the ordinary least square assumptions are being met. Satisfying these assumptions indicates the ordinary least squares regression will produce unbiased coefficient estimates with the minimum variance. Normal probability plots of residuals, residuals versus fits and residuals versus order of data were plotted in Minitab. Normal probability plot of residuals shows that our data is distributed normally.

\section{CONCLUSIONS}

Adsorption of Chlorsulfuron was seen to be increasing with augmented pesticides concentration. Soil physiochemical properties play great role in adsorption and desorption i.e. organic matter, $\mathrm{pH}$ and clay content. Statistical tool ANOVA, MS Office Excel Correlation and Regression analysis were utilized to further study the role of soils' physicochemical make up on Chlorsulfuron make up. Adsorption distribution coefficient $K_{d}$ value was low demonstrating less interaction between Chlorsulfuron and soil particles. Soil 2 exhibited the highest value of $\mathrm{K}_{d}$ i.e. $23.0 \mu \mathrm{g} / \mathrm{ml}$. For desorption $\mathrm{K}_{\mathrm{d}(\mathrm{des})}$ showed higher values indicating its inverse relation with $\mathrm{K}_{\mathrm{d}(\mathrm{ads})}$ and thus sample 2 showed lowest value of $\mathrm{K}_{\mathrm{d}(\mathrm{des})}$ i.e. $7.83 \mu \mathrm{g} / \mathrm{ml}$. $\mathrm{K}_{\text {foc }}$ values were large which means that the herbicide showed less mobility in soil with more clay content and these differences in sorption of Chlorsulfuron in different soils can be associated with physicochemical properties of soil mainly organic matter, $\mathrm{pH}$ and CEC. Linear and Freundlich correlation and regression analysis showed positively correlationship between adsorption coefficients and organic matter, total organic content and clay while $\mathrm{pH}$ negatively impacted adsorption. 
INVESTIGATING THE IMPACT OF SOILS' PHYSICOCHEMICAL COMPOSITION ON ...

\section{EXPERIMENTAL SECTION}

99.9\% pure analytical grade Acetone, Methanol, Anhydrous powder of Sodium Chloride and Calcium Chloride, Concentrated Hydrogen peroxide 35\%, Concentrated Hydrochloric acid, Nitric acid, Ammonium acetate and Sodium Hydrogen Carbonate were obtained from Sigma-Aldrich (Steinheim, Germany). Analytical standard Chlorsulfuron was purchased from ACCU Standard USA. While the instruments used were; Weighting machine (AUX220, Shimadzu, U.S.A), Hot air drier (UN55plus, Memmert, Germany), Octagonal sieve shaker (Octagon200, Endecotts, UK), pH meter (pH 7110, WTW Ino Labs, Germany), EC meter (525-A, Crison, Spain), Furnace (JFF-2000, Ncycraft, U.S.A), Orbital and incubator shaker (2102, Irmeco Gmbh, Germany), Centrifuge (26-E, Hettich, U.S.A), Hot plate (MSH-20D, Wisestir, Germany) and UV-Visible spectrophotometer (BMS-1602, Biotechnology Medical Services K. Group, U.S.A). Soil sampling was done by collection of 7 soil subsamples of $4 \mathrm{~kg}$ from four geographically distinct areas of Bahawalpur (Punjab) Sample 1, Gilgit (Gilgit-Baltistan) Sample 2, Swabi (Khyber Pukhtoonkhwa) Sample 3, Sialkot (Punjab) Sample 4, Random sampling was carried out by selecting some specific points of each district followed by evaluation of physicochemical parameters [23].

Adsorption and desorption experiments was performed with $1 \mathrm{mM}$ Chlorsulfuron solution with neutral $\mathrm{pH}$ at room temperature. Each experiment was performed with duplicated and the mean value was used. The solution was photometrically checked with UV-Vis Spectrphotometer. Further eight dilutions i.e. $0 \mathrm{ppm}, 0.25 \mathrm{ppm}, 0.5 \mathrm{ppm}, 0.75 \mathrm{ppm}, 1.0 \mathrm{ppm}, 2.5 \mathrm{ppm}, 5.0 \mathrm{ppm}$ and $7.5 \mathrm{ppm}$ were prepared and $0.1 \mathrm{mM} \mathrm{NaCl}$ was added as background electrolyte. Pesticide dilutions were prepared with $10 \mathrm{ml}$ pesticide in soils by keeping ratio $1: 20$ for soil/pesticide solution. The assemblage was shaked for 24 hours and then centrifuged prior to UV-Vis Spectrophotometry [16]. Desorption studies were performed on the same pesticide-soil solution. The tubes were reweighed after supernatant decantation. $9 \mathrm{ml}$ of freshly prepared $0.01 \mathrm{M} \mathrm{CaCl} \mathrm{Cl}_{2}$ solution was added followed by 24 hours shaking and centrifugation prior to photometric analysis [16].

\section{REFERENCES}

1. K.S. Ahmad, N. Rashid, M. Zakria, Journal of the Chemical Society of Pakistan, 2015, 37, 380.

2. M. Sarwar, International Journal of Bioinformatics and Biomedical Engineering, 2015, 1, 130. 
3. Y. Liu, X. Pan, J. Li, Agronomy for Sustainable Development, 2015, 35, 83.

4. C. A. Damalas, Journal of Food Saftety, 2016, 43.

5. C. Wu, S. Zhang, G. Nie, Z. Zhang, J. Wang, Journal of Environmental Science, 2011, 23, 1524.

6. V.H. Springer, A.G. Lista, Talanta, 2010, 83, 126.

7. S. Kaczmerek, K. Matysiak, Journal of Plant Research, 2015, 55, 8.

8. J. Mankowski, K. Pudelko, Industrial Crops and Products, 2015, 70, 185.

9. U. Eugen, F. Lipşa, I.P. Chiriac, I.G. Coroi, Lucrări Ştiinţifice, 2010, 53, 157.

10. C.A. Mallory-Smith, D.C. Thill, M.J. Dial, Weed Technology, 1990, 4, 163.

11. M.A. Martinez-Ghersa, C.M. Ghersa, R.L. Benech-Arnold, R. Mac Donough, R.A. Sanches, Plant Species Biology, 2010, 15, 127.

12. Heap, Proceedings of an international conference, Brighton, UK, 2015.

13. Szmigielski, B. Geisel, E. Johnson, F. Holm, J. Schoenau, (2011). "Application of a laboratory bioassay for assessment of bioactivity of ALS-inhibiting herbicides in soil”. INTECH Open Access Publisher, 2011, chapter 7.

14. M.S. Başaran, A. T. Serim, Selçuk Journal of Agriculture and Food Sciences, 2010, 24, 54.

15. A. Vicari, P. Catizone, R.L. Zimdahl, Weed Research, 1994, 34, 147.

16. K.S. Ahmad, N. Rashid, S. Tazaiyen, M. Zakria, Journal of the Chemical Society of Pakistan, 2014, 36, 1189.

17. B. Gevao, K.T. Semple, K.C. Jones, Environmental Pollution, 2000, 108, 3.

18. K.S. Ahmad, N. Rashid, M.F. Nazar, S. Tazaiyen, Journal of the Chemical Society of Pakistan, 2013, 34, 1017.

19. Y. Liu, Z. Xu, X. Wu, W. Gui, G. Zhu, Journal of hazardous materials, 2010, $178,462$.

20. M. Kumar, L. Philip, Chemosphere, 2006, 62, 1064.

21. C. Flores, V. Morgante, M. González, R. Navia, M. Seeger, Chemosphere, 2009, $74,1544$.

22. K.A. Sudduth, S.T. Drummond, N.R. Kitchen, Computers and Electronics in Agriculture, 2001, 31, 239.

23. M.Y. Corapciogluand, A.L. Baehr, Water Resources Research, 1987, 23, 191. 